\title{
Article \\ Effects of High-Volume Ground Slag Powder on the Properties of High-Strength Concrete under Different Curing Conditions
}

\author{
Yuqi Zhou ${ }^{1,2}$, Jianwei Sun ${ }^{2,3, *}$ and Zengqi Zhang ${ }^{4}$ \\ 1 China Construction First Group Construction and Development Co., Ltd., Beijing 100102, China; \\ zhouyuqi@chinaonebuild.com \\ 2 Department of Civil Engineering, Tsinghua University, Beijing 100084, China \\ 3 School of Civil Engineering, Qingdao University of Technology, Qingdao 266033, China \\ 4 School of Metallurgical and Ecological Engineering, University of Science and Technology Beijing, \\ Beijing 100083, China; zzq4816@163.com \\ * Correspondence: jianwei_68@126.com
}

check for

updates

Citation: Zhou, Y.; Sun, J.; Zhang, Z. Effects of High-Volume Ground Slag Powder on the Properties of

High-Strength Concrete under Different Curing Conditions. Crystals 2021, 11, 348. https://doi.org/ $10.3390 /$ cryst11040348

Academic Editors: Yifeng Ling, Chuanqing Fu, Peng Zhang and Peter Taylor

Received: 7 March 2021

Accepted: 25 March 2021

Published: 29 March 2021

Publisher's Note: MDPI stays neutral with regard to jurisdictional claims in published maps and institutional affiliations.

Copyright: (c) 2021 by the authors. Licensee MDPI, Basel, Switzerland. This article is an open access article distributed under the terms and conditions of the Creative Commons Attribution (CC BY) license (https:/ / creativecommons.org/licenses/by/ $4.0 /)$.

\begin{abstract}
Massive high-strength concrete structures tend to have a high risk of cracking. Ground slag powder (GSP), a sustainable and green industrial waste, is suitable for high-strength concrete. We carried out an experimental study of the effects of GSP with a specific surface area of $659 \mathrm{~m}^{2} / \mathrm{kg}$ on the hydration, pore structure, compressive strength and chloride ion penetrability resistance of high-strength concrete. Results show that adding 25\% GSP increases the adiabatic temperature rise of high-strength concrete, whereas adding $45 \%$ GSP decreases the initial temperature rise. Incorporating GSP refines the pore structure to the greatest extent and improves the compressive strength and chloride ion penetrability resistance of high-strength concrete, which is more obvious under early temperature-matching curing conditions. Increasing curing temperature has a more obvious impact on the pozzolanic reaction of GSP than cement hydration. From a comprehensive perspective, GSP has potential applications in the cleaner production of green high-strength concrete.
\end{abstract}

Keywords: GSP; high strength; hydration; strength; penetrability

\section{Introduction}

Currently, high-rise buildings have become increasingly widespread in China due to their advantages in space, stability and unique design [1,2]. They typically symbolize the landscape architecture and construction of a city, such as the Shanghai Tower (632 $\mathrm{m})$, the Shenzhen Ping'an Finance Centre (599 m) and the China Zun in Beijing (528 m). The foundation structures of high-rise buildings with heavy loads are extremely deep and wide, which is typical for massive high-strength concrete structures [1]. During the hydration process, substantial hydration heat is generated in massive high-strength concrete, resulting in a high internal temperature rise because of its slow heat dissipation [3-6]. After hardening, large tensile stresses are formed due to restrained thermal and autogenous shrinkage deformations, which are the main driving forces of cracking in concrete [7].

Using supplementary cementitious materials (SCMs) to lower early heat and attendant volume changes is the most common preventative method [8-12]. The application of SCMs in concrete also has positive effects on workability, pumpability, strength and permeability resistance to chemical attacks [13-21]. Meanwhile, SCMs, as mineral admixtures to replace cement in high-strength concrete, reduce the carbon footprint in cement and concrete production and are conducive to sustainable development due to the conservation of natural resources [22-24]. Slag, as one of the most suitable SCMs, has been extensively identified and used to directly replace cement, minimizing cracking in massive concrete applications. Slag is a non-metallic residual generated from blast furnaces when iron is extracted from its ore $[25,26]$. Molten slag, comprising mostly silicates and alumina, is swiftly quenched with abundant water [27]. The rapid cooling method results in amorphous phases of slag (nearly 
$80 \%$ content), which is responsible for its pozzolanic activity [28]. Compared to Portland cement, slag has a lower specific gravity [29]. The colour of slag varies from dark grey to white depending on the moisture inside, its chemical composition and its granulation efficiency [30]. The replacement rate for slag during the production of concrete varies from $30 \%$ to $85 \%$, and $50 \%$ is typically used in most applications [10,31]. Incorporating as little as 30\% slag can reduce the cumulative heat by $25 \%$ after the initial $48 \mathrm{~h}[31,32]$. The cementitious activity of slag needs to be further improved for wider application. These inherent attributes are not easy to change, including the chemical composition, amorphous phase content and alkali concentration of the cement system [33,34]. However, the fineness of slag can be further enhanced by drying and subsequent grinding in a rotating ball mill to a finer powder with a specific surface area of $600 \mathrm{~m}^{2} / \mathrm{kg}-700 \mathrm{~m}^{2} / \mathrm{kg}$, which is called "ground slag powder (GSP)" in this study.

Many studies have proven that the pozzolanic reaction rate is increased by improving the fineness of slag, which has a great impact on the development of strength and durability. He et al. [35] used two methods to prepare GSP, including the wet-milling method and the dry-separation method, to improve its early reactivity. They verified that the setting time gradually decreased with the dry-separation slag and increased with the wet-milling slag [35]. Moreover, a system containing wet-milling slag had higher electrical resistivity and better mechanical properties [35]. Liu et al. [36] investigated the contribution ratios of GSP to a GSP-cement-steel slag ternary cementitious material system and found that GSP caused an obvious improvement in the hydration and mechanical properties at every stage due to its close-packing effect [36]. Zhang et al. [37] found that the ultimate hydration heat initially increased and then decreased sharply with increasing proportions of GSP [37]. Meanwhile, adding GSP had a slight impact on chemical shrinkage but increased the chloride binding capacity [37]. Mohan et al. [38] conducted experiments on the influence of silica fume and GSP on the properties of self-compacting concrete. They found that incorporating GSP is a better way to decrease free shrinkage due to the diminished water withholding and improved sulphate and acid attack resistance of self-compacting concrete [38]. Pradeep Kumar et al. [39] reported a modification of the corrosion property of concrete with the use of GSP. Using GSP reduced the workability and water absorption of concrete, enhanced the bond strength of the steel rebar, and remarkably reduced rebar corrosion [39].

Based on the literature available, there is still a lack of research on the properties of GSP high-strength concrete. Hence, this study aims to investigate the feasibility of using GSP as a mineral admixture in high-strength concrete. In this paper, high-strength cement concrete with a design strength of C75 was prepared as the reference sample. Two substitution rates of GSP ( $25 \%$ and $45 \%$ ) and two curing conditions (a standard curing condition and a temperature-matching curing condition) were selected. The adiabatic temperature rise, pore structure, hydration products, compressive strength and chloride ion penetrability resistance of high-strength concrete were measured. Effects of elevated early temperatures on the properties of plain cement concrete and GSP concrete were analyzed. The results of this study can provide considerable theoretical guidance for the use of GSP in massive high-strength concrete applications.

\section{Materials and Methods}

\subsection{Raw Materials}

Water-quenched blast-furnace slag powder was produced by Xingye Materials Co., Ltd., Xingtai, Hebei province, China. Portland cement with a strength grade of 42.5 was supplied by Jinyu Cement Co., Ltd., Beijing, China. The slag powder is further ground into GSP in the laboratory. The chemical compositions of raw materials are given in Table 1. The mass coefficient $\left(\mathrm{K}=\mathrm{w}\left(\mathrm{CaO}+\mathrm{MgO}+\mathrm{Al}_{2} \mathrm{O}_{3}\right) / \mathrm{w}\left(\mathrm{SiO}_{2}+\mathrm{MnO}+\mathrm{TiO}_{2}\right)\right)$ of the GSP used was 1.97 according to the Chinese national standard (GB/T 203-2008). The specific surface areas of the cement and GSP were $341 \mathrm{~m}^{2} / \mathrm{kg}$ and $659 \mathrm{~m}^{2} / \mathrm{kg}$, respectively. Coarse aggregates of concrete are crushed limestone of 5 to $20 \mathrm{~mm}$ in size. Fine aggregates of 
concrete are river sand with a fineness modulus of 2.9. The workability of fresh concrete was adjusted using a polycarboxylate superplasticizer.

Table 1. Chemical compositions of the cement and ground slag powder (GSP)/\%.

\begin{tabular}{cccccccccc}
\hline & $\mathrm{CaO}$ & $\mathrm{SiO}_{2}$ & $\mathrm{Al}_{\mathbf{2}} \mathrm{O}_{3}$ & $\mathbf{M g O}$ & $\mathrm{Fe}_{2} \mathrm{O}_{3}$ & $\mathrm{SO}_{3}$ & $\mathrm{Na}_{\mathbf{2}} \mathrm{O}_{\text {eq }}{ }^{*}$ & $\mathbf{f - C a O}$ & $\mathrm{LOI}$ \\
\hline Cement & 62.71 & 22.33 & 4.75 & 1.98 & 2.78 & 2.37 & 0.68 & 0.64 & 2.03 \\
$\mathrm{GSP}$ & 39.47 & 30.14 & 18.64 & 8.68 & 0.75 & 0.24 & 0.86 & - & 1.04 \\
\hline${ }^{*} \mathrm{Na}_{2} \mathrm{O}_{\mathrm{eq}}=\mathrm{Na}_{2} \mathrm{O}+0.658 \mathrm{~K}_{2} \mathrm{O}$; LOI: loss on ignition.
\end{tabular}

\subsection{Mix Proportions}

Table 2 shows the mix proportions of the high-strength concrete. The total amount of binder was $550 \mathrm{~kg} / \mathrm{m}^{3}$. A water/binder ratio of 0.28 and a sand ratio of 0.43 were selected. Plain cement concrete was regarded as the reference sample (sample C). Two substitution rates of GSP ( $25 \%$ and $45 \%$ by mass) were used, corresponding to sample S25 and sample S45. Cubic concrete samples with side lengths of $100 \mathrm{~mm}$ were prepared. Each sample had a total of 36 square concrete specimens. The paste had the same water/binder ratio and substitution rates as the concrete. Fresh pastes were cast into plastic tubes and cured under the same curing conditions as the concrete.

Table 2. Mix proportions of high-strength concrete $/ \mathrm{kg} \cdot \mathrm{m}^{-3}$.

\begin{tabular}{ccccccc}
\hline Sample & Cement & GSP & $\begin{array}{c}\text { Fine } \\
\text { Aggregate }\end{array}$ & $\begin{array}{c}\text { Coarse } \\
\text { Aggregate }\end{array}$ & Water & Superplasticizer \\
\hline C & 550 & - & 751 & 995 & 154 & 5.5 \\
S25 & 412.5 & 137.5 & 751 & 995 & 154 & 8.25 \\
S45 & 302.5 & 247.5 & 751 & 995 & 154 & 11 \\
\hline
\end{tabular}

\subsection{Curing Conditions and Test Methods}

In this study, two curing conditions for the concretes and pastes were set-the standard curing condition (symbol S) and the temperature-matching curing condition (symbol M). Thus, sample SS25 represents S25 concrete cured under the standard curing condition, and sample MS45 represents S45 concrete cured under the temperature-matching curing condition. The standard curing condition required a constant temperature $\left(20^{\circ} \mathrm{C} \pm 2{ }^{\circ} \mathrm{C}\right)$ and relative humidity ( $>95 \%$ ). The temperature-matching curing condition needed to be adjusted according to the adiabatic temperature rise curve of the concrete. The adiabatic temperature rise curve of high-strength concrete for the initial $7 \mathrm{~d}$ was determined by a temperature measuring instrument $(50 \mathrm{~L})$ with an accuracy of $\pm 0.1{ }^{\circ} \mathrm{C}$.

The compressive strength and chloride ion penetrability resistance of concrete for each concrete mixture were obtained from an average of three specimens. The pastes were prepared for the tests of pore structure, $\mathrm{Ca}(\mathrm{OH})_{2}(\mathrm{CH})$ content, and non-evaporable water content. First, the hardened paste was broken into small pieces (less than $5 \mathrm{~mm}$ ). Then, the pieces were soaked in ethanol (Tongguang fine chemicals company, Beijing, China) for $24 \mathrm{~h}$ at test ages. Finally, all pieces were dried in the oven at $110^{\circ} \mathrm{C}$. For tests of $\mathrm{CH}$ content and non-evaporable content water content, dried pieces were further ground into ultrafine powder. The pore structure of hardened paste at ages of $28 \mathrm{~d}$ and $90 \mathrm{~d}$ was measured with a mercury intrusion porometer (MIP, AUTOPORE II 9220 manufactured by Micromeritics, America) with a maximum mercury intrusion pressure of $300 \mathrm{MPa}$. The $\mathrm{CH}$ content was determined by thermogravimetric (TG) and derivative thermogravimetric (DTG) analyses. TG and DTG curves were obtained using Instrument TGA 3+ (METTLER TOLEDO, Switzerland) in an $\mathrm{N}_{2}$ atmosphere from $30{ }^{\circ} \mathrm{C}$ to $900{ }^{\circ} \mathrm{C}$ at $14 \mathrm{~d}, 28 \mathrm{~d}$ and $90 \mathrm{~d}$. The non-evaporable water content $W_{n}$ was determined using the following Equation (1):

$$
\mathrm{W}_{\mathrm{n}}=\left(\mathrm{m}_{1}-\mathrm{m}_{2}\right) / \mathrm{m}_{1}-(1-\alpha) \mathrm{LOI}_{\mathrm{C}}-\alpha \mathrm{LOI}_{\mathrm{S}},
$$


where $\mathrm{m}_{1}$ is the dried mass of hardened paste at $110{ }^{\circ} \mathrm{C}, \mathrm{m}_{2}$ is the mass of hardened paste after heating at $1050{ }^{\circ} \mathrm{C}, \alpha$ represents the replacement rate of GSP, and $\mathrm{LOI}_{C}$ and $\mathrm{LOI}_{S}$ represent the loss on ignition of cement and GSP, respectively.

\section{Results and Discussion}

\subsection{Adiabatic Temperature Rise}

The adiabatic temperature rise curves of plain cement concrete and GSP concrete for the initial $7 \mathrm{~d}$ are depicted in Figure 1. It is obvious that the growth trends of the three temperature curves are similar. The temperature rose sharply before $24 \mathrm{~h}$ and remained stable after $150 \mathrm{~h}$. The final temperature rises of samples C, S25 and S45 were $56.56{ }^{\circ} \mathrm{C}, 60.58{ }^{\circ} \mathrm{C}$ and $54.07{ }^{\circ} \mathrm{C}$, respectively. This illustrates that the incorporation of $25 \%$ GSP increases the adiabatic temperature rise by $4.02{ }^{\circ} \mathrm{C}$ and incorporating $45 \%$ GSP decreases the adiabatic temperature rise by $2.49^{\circ} \mathrm{C}$. Note that sample S25 exhibited the maximum temperature rise. This indicates that the promoting effect of GSP on cement hydration exceeds the negative effect due to cement reduction. The promoting effects derived from two main contributing factors [34]. One is the heterogenous nucleation effect [34]. Compared to cement particles, GSP has finer particles, of which the specific surface area is $659 \mathrm{~m}^{2} / \mathrm{kg}$. Finer slag particles can serve as heterogeneous nucleation and crystallization sites of $\mathrm{C}-\mathrm{S}-\mathrm{H}$ gel and $\mathrm{CH}$, thus improving the degree of cement hydration. The other is related to the higher reactivity of slag, which participates in pozzolanic reactions at an early stage, thus promoting cement hydration. The drop in the adiabatic temperature rise is attributed to a significant reduction in cement content.

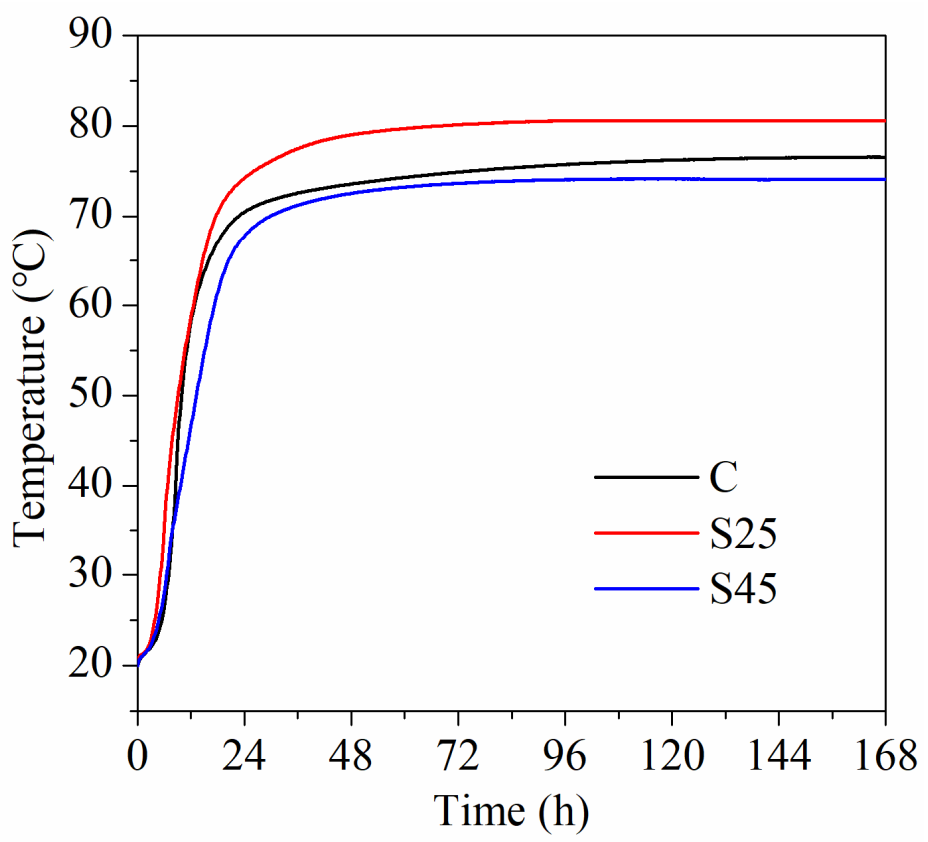

Figure 1. Adiabatic temperature rise curves of concrete.

\subsection{Compressive Strength}

The compressive strengths of plain cement concrete and GSP concrete under standard curing conditions are shown in Figure 2a. It can be easily observed that the compressive strength of concrete slightly increased with GSP at all ages. The compressive strengths of concrete at ages of $7 \mathrm{~d}, 28 \mathrm{~d}, 90 \mathrm{~d}$ and $180 \mathrm{~d}$ were more than $70 \mathrm{MPa}$, approximately $80 \mathrm{MPa}, 85 \mathrm{MPa}$ and $90 \mathrm{MPa}$, respectively. Compared to the $7 \mathrm{~d}$ compressive strength, the growth rates of the strength at the ages of $28 \mathrm{~d}, 90 \mathrm{~d}$ and $180 \mathrm{~d}$ were approximately $12 \%$, $20 \%$ and $24 \%$, respectively. Thus, the growth rates of the compressive strengths of plain cement concrete and GSP concrete showed little difference at the same ages under standard curing conditions. Compared to the compressive strengths of plain cement concrete, the 
growth rates in strength due to the addition of GSP were calculated and are presented in Figure $2 \mathrm{~b}$. The growth rate of sample SS25 at all ages was relatively low, at no more than $2 \%$. The growth rate of sample SS45 was higher than that of sample SS25 at all ages. In particular, the $28 \mathrm{~d}$ growth rate of sample SS45 reached 6\%. The growth rate is related to pore structure and hydration products. Compared to sample SS25, sample SS45 has a higher substitution rate and the presence of GSP with finer particles has a more positive influence on early hydration, resulting in a higher growth rate.

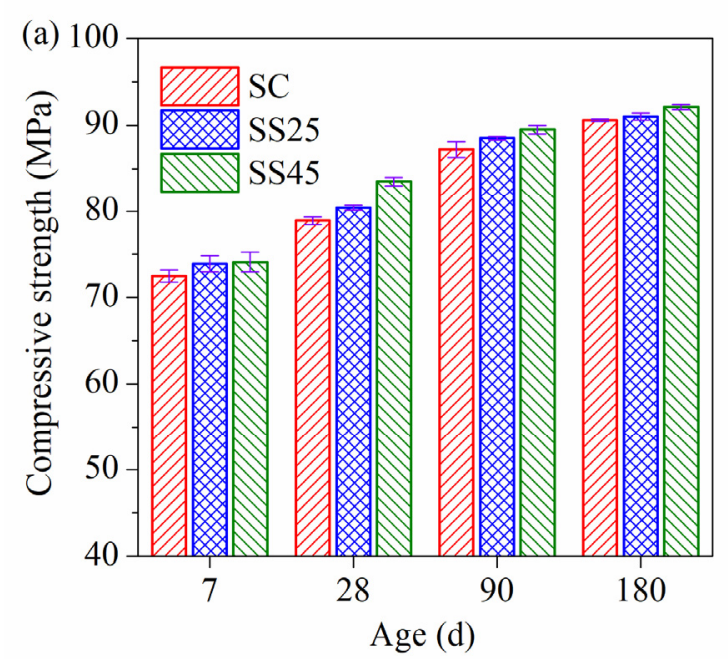

(a)

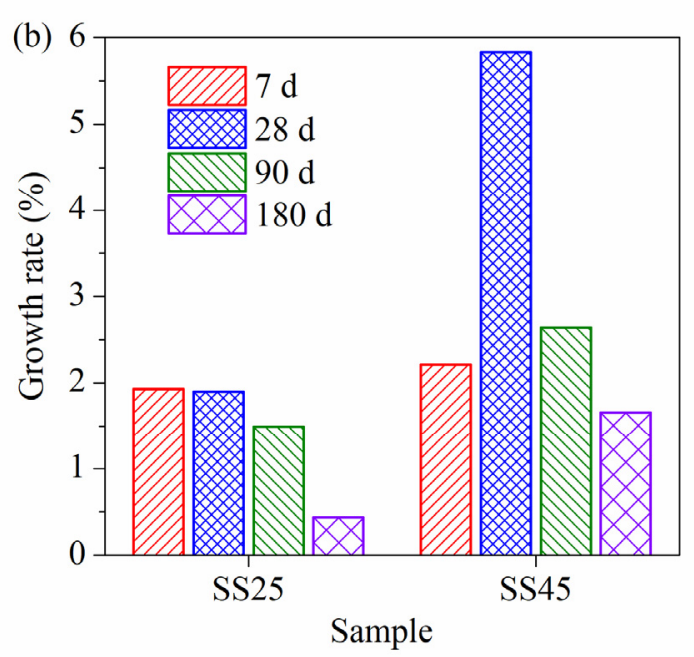

(b)

Figure 2. (a) Compressive strength of high-strength concrete under standard curing condition; (b) growth rate of compressive strength at different ages.

The compressive strength and growth rate of compressive strength under temperaturematching curing conditions are presented in Figure $3 \mathrm{a}, \mathrm{b}$, respectively. The compressive strength of high-strength concrete significantly increases with GSP at all ages under temperature-matching curing conditions, which is different from the trend under standard curing conditions. Compared to the $7 \mathrm{~d}$ compressive strength, the growth rates of the strength at $28 \mathrm{~d}$ and $90 \mathrm{~d}$ were approximately $11 \%$ and $21 \%$, respectively. However, the growth rates of $180 \mathrm{~d}$ compressive strength were approximately $22 \%, 28 \%$ and $30 \%$, respectively. The growth rate of GSP concrete at $180 \mathrm{~d}$ was higher than that of plain cement concrete. Meanwhile, compared to the compressive strength of plain cement concrete, the growth rates of strength at different ages due to the addition of GSP under temperaturematching curing conditions (Figure $3 \mathrm{~b}$ ) were higher than those under standard curing temperatures (Figure 2b). In addition, the growth rate increased with GSP. In particular, the $180 \mathrm{~d}$ growth rates were the highest. This result indicates that the temperature-matching curing conditions have a more positive effect on the development of the late compressive strength of GSP concrete. Elevated temperatures promote the pozzolanic reaction of GSP. The pozzolanic reaction of GSP consumes $\mathrm{CH}$ and forms $\mathrm{C}-\mathrm{S}-\mathrm{H}$ gel, improving the density of the interfacial transition zone between the cement and aggregates [40,41]. Furthermore, C-S-H gel plays a key role in mechanical performance. When GSP is added to the cementitious system, $\mathrm{Al} 3+$ is released from the slag and finally forms a $\mathrm{C}-(\mathrm{A})-\mathrm{S}-\mathrm{H}$ gel, leading to an increase in the $\mathrm{Al} / \mathrm{Si}$ molar ratio and a decrease in the $\mathrm{Ca} / \mathrm{Si}$ molar ratio [42,43]. C-S-H with higher $\mathrm{Al} / \mathrm{Si}$ and lower $\mathrm{Ca} / \mathrm{Si}$ ratios has a higher bonding capacity and thus improves the compressive strength [40-44]. 


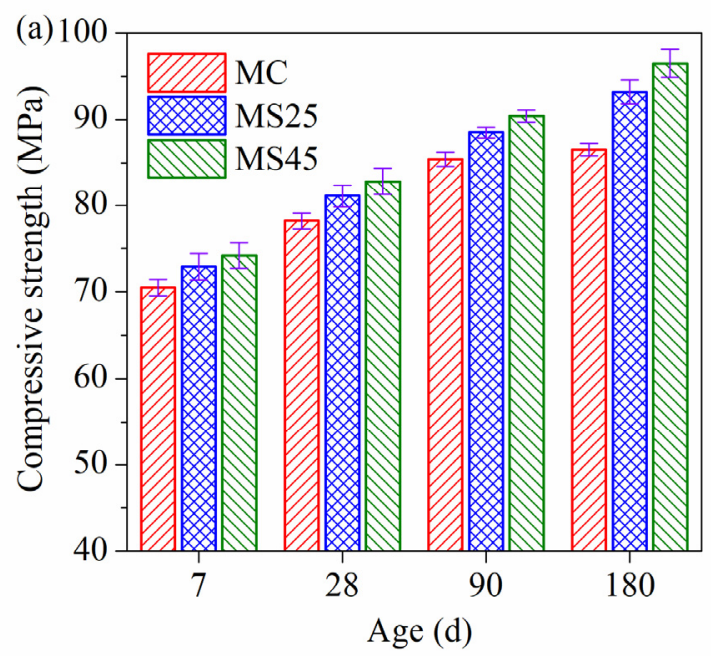

(a)

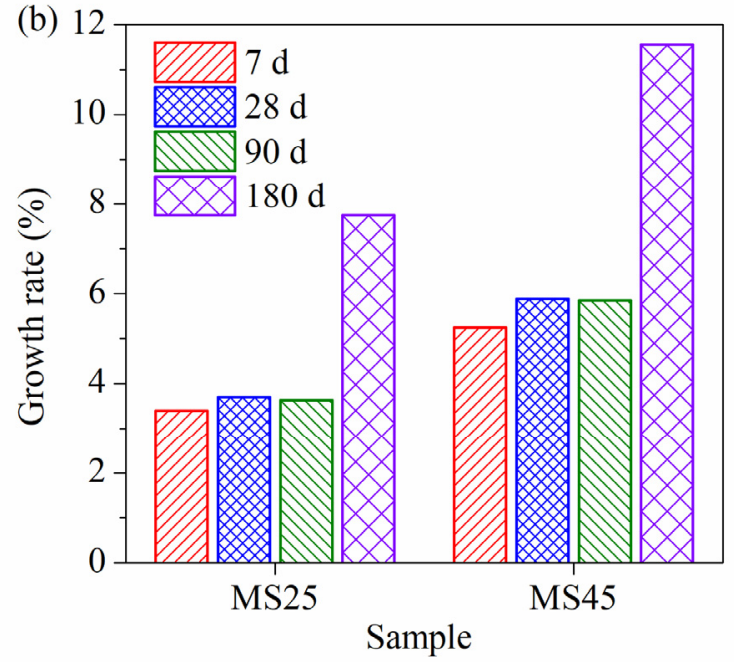

(b)

Figure 3. (a) Compressive strength of high-strength concrete under temperature-matching curing conditions; (b) growth rate of compressive strength at different ages.

\subsection{Chloride Ion Penetrability Resistance}

The chloride ion penetrability resistance of concrete at ages of $28 \mathrm{~d}$ and $180 \mathrm{~d}$ under standard curing conditions are shown in Figure 4 . It can be seen in Figure 4 that the chloride ion penetrability grades of sample SC were "moderate" and "low" at $28 \mathrm{~d}$ and $180 \mathrm{~d}$, respectively. However, the penetrability grades of samples SS25 and SS45 fell to the "low" level and the "very low" level at the two ages. Therefore, substitution with GSP can improve the chloride ion penetrability resistance of high-strength concrete, and the effect increases with increasing GSP. This is because the filling effect of grinding slag fills the pore structure of concrete, and the pozzolanic reaction consumes $\mathrm{CH}$ in the transition zone, resulting in more $\mathrm{C}-\mathrm{S}-\mathrm{H}$ gel, which refines the pore structure.

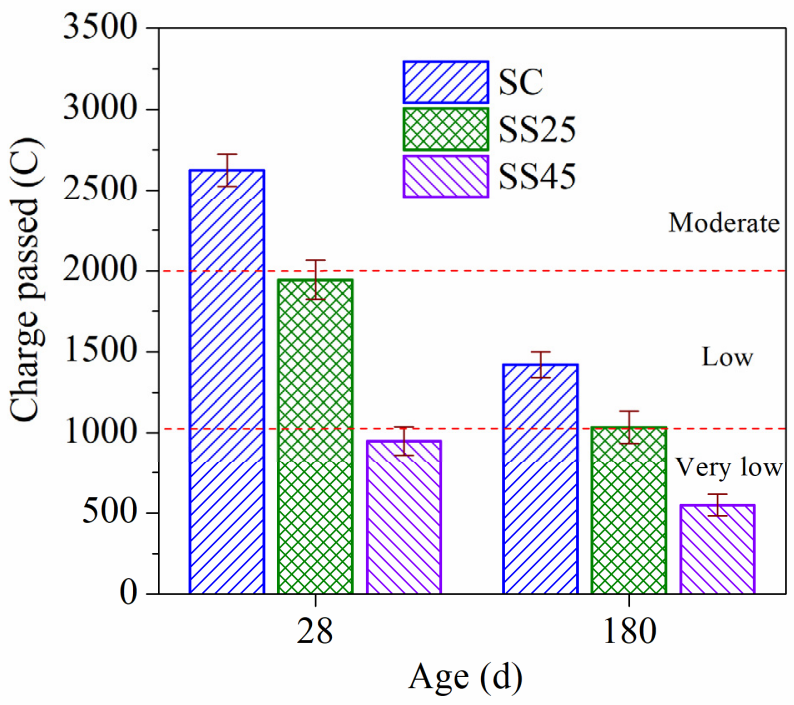

Figure 4. Chloride ion penetrability resistance of high-strength concrete under standard curing conditions.

The chloride ion penetrability resistance of concrete at $28 \mathrm{~d}$ and $180 \mathrm{~d}$ under temperaturematching curing conditions are presented in Figure 5. Significantly, as the age increases, the chloride ion penetration resistance of concrete did not change. The chloride ion pene- 
trability grades of sample MC were "moderate" at the two ages. The penetrability grades of both samples MS25 and MS45 fell to the "very low" level at the same time. The GSP content has little effect on the chloride ion penetration resistance of concrete with further hydration. This is because the pozzolanic reaction of GSP mainly occurred at an early age and increasing the early curing temperature promoted the reaction of GSP, which had an adverse effect on the late reaction. In terms of the chloride ion penetration resistance, combined with the results under standard curing conditions, increasing the curing temperature has a greater influence on high-strength concrete mixed with 25\% GSP.

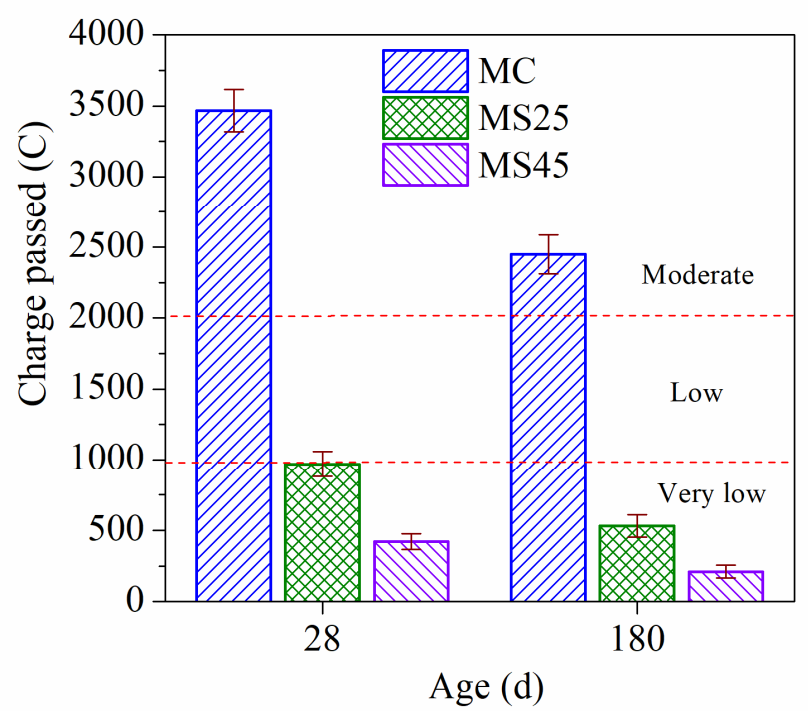

Figure 5. Chloride ion penetrability resistance of high-strength concrete under temperature-matching curing conditions.

\subsection{Pore Structure}

The differential pore size distributions of different hardened pastes under standard curing conditions are presented in Figure 6. As shown in Figure 6, the most likely pore sizes of samples SC, SS25 and SS45 at $28 \mathrm{~d}$ were $62.1 \mathrm{~nm}, 30.2 \mathrm{~nm}$ and $13.94 \mathrm{~nm}$, respectively. With further hydration, the pore structure of the hardened paste becomes dense. The most likely pore sizes of samples SC, SS25 and SS45 at $28 \mathrm{~d}$ were $40.7 \mathrm{~nm}, 5.42 \mathrm{~nm}$ and $3.39 \mathrm{~nm}$, respectively. The most likely pore size obviously decreased with GSP due to its positive effects on pore structure. Pores in hardened paste can be divided into four types, depending on their diameters and functions, according to Mehta's opinion: $>100 \mathrm{~nm}$, $50-100 \mathrm{~nm}, 4.5-50 \mathrm{~nm}$ and $<4.5 \mathrm{~nm}[45,46]$. Pores larger than $100 \mathrm{~nm}$ (also called harmful pores) have adverse effects on the development of mechanical strength and the permeability of hardened matrices [36]. Thus, the detailed pore size distribution of the hardened paste is presented in Figure 7. Figure 7a shows that the porosities of samples SC, SS25 and SS45 at $28 \mathrm{~d}$ were $21.52 \%, 20.81 \%$ and $17.29 \%$, respectively. The porosities at $90 \mathrm{~d}$, shown in Figure $7 \mathrm{~b}$, were $16.77 \%, 16.79 \%$ and $19.09 \%$, respectively. Compared to the plain cement paste (sample SC), the total porosity and the volume of harmful pores in hardened paste at $28 \mathrm{~d}$ were significantly reduced due to the addition of GSP. However, the total porosity in hardened paste containing $45 \%$ GSP (sample SS45) was the largest at $28 \mathrm{~d}$ due to more harmless pores $(<4.5 \mathrm{~nm})$. 


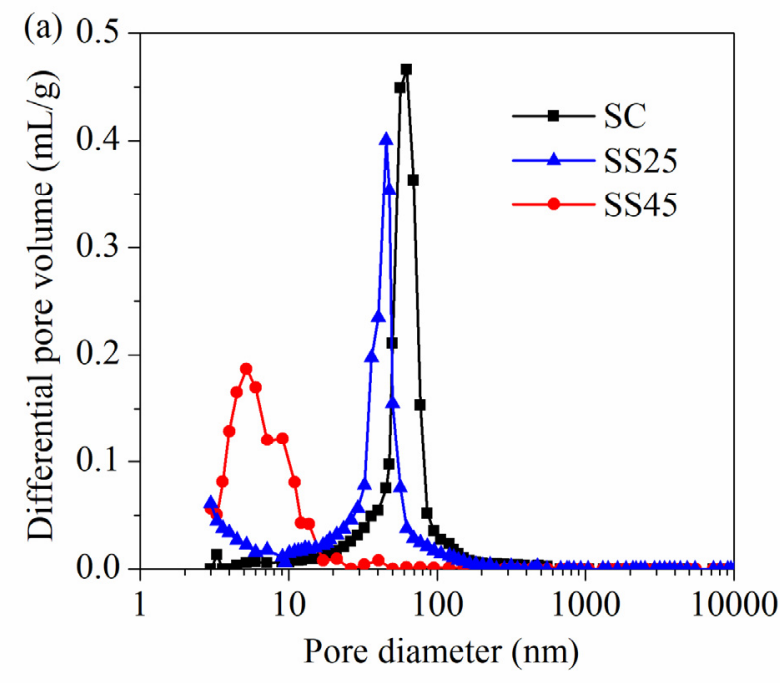

(a)

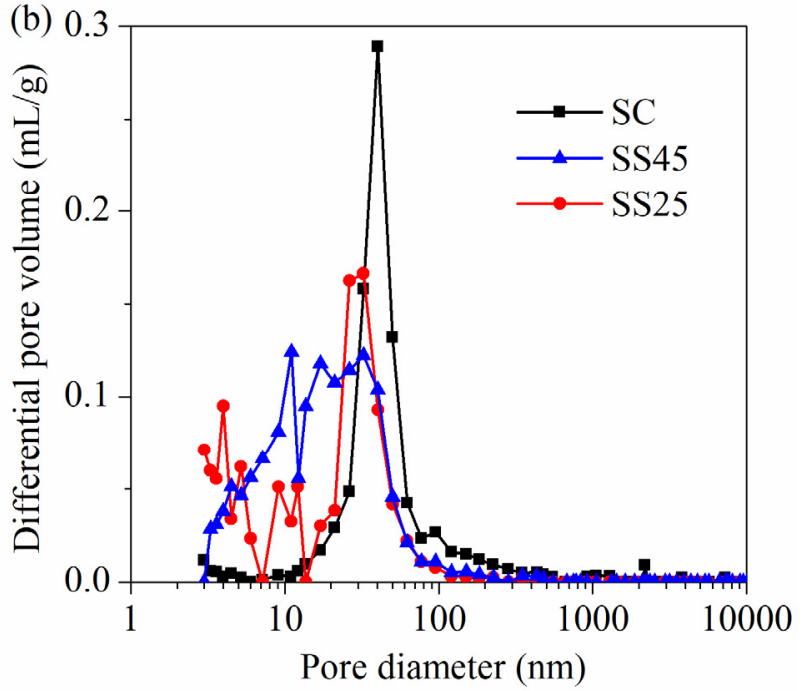

(b)

Figure 6. Differential pore volume of hardened pastes under standard curing conditions: (a) at $28 \mathrm{~d}$; (b) at $90 \mathrm{~d}$.

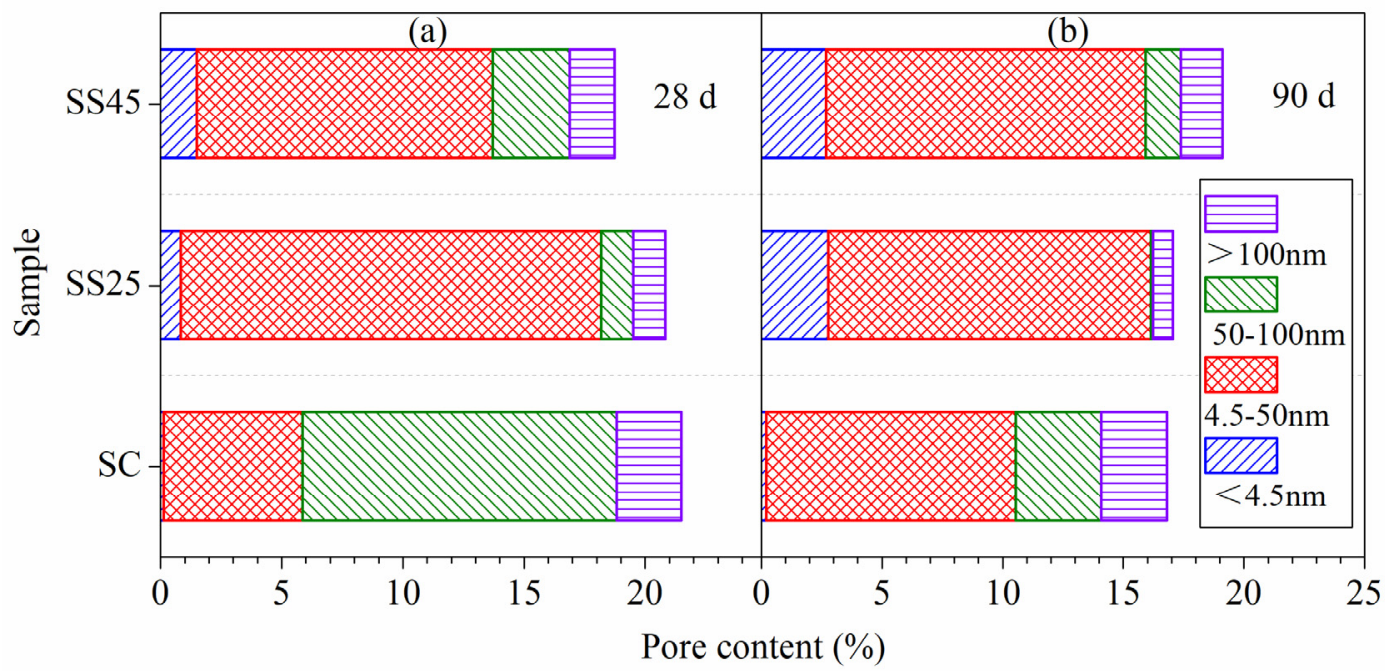

Figure 7. The pore size distribution of hardened pastes under standard curing conditions: (a) at $28 \mathrm{~d} ;(\mathbf{b})$ at $90 \mathrm{~d}$.

The differential pore size distributions of different hardened pastes under temperaturematching curing conditions are presented in Figure 8. The most likely pore sizes of samples MC, MS25 and MS45 at $28 \mathrm{~d}$ were $24.3 \mathrm{~nm}, 49.0 \mathrm{~nm}$ and $5.4 \mathrm{~nm}$, respectively. With further hydration, the pore structure of the hardened paste becomes denser. The most likely pore sizes of samples MC, MS25 and MS45 at $90 \mathrm{~d}$ were $17.1 \mathrm{~nm}, 5.7 \mathrm{~nm}$ and $5.0 \mathrm{~nm}$, respectively. The detailed pore size distribution of the hardened paste is presented in Figure 9. Figure 9a shows that the porosities of samples MC, MS25 and MS45 at $28 \mathrm{~d}$ were $24.74 \%, 17.09 \%$ and $16.23 \%$, respectively. The porosities at $90 \mathrm{~d}$, shown in Figure $9 \mathrm{~b}$, were $22.20 \%, 16.35 \%$ and $11.31 \%$, respectively. Compared to the plain cement paste (sample MC), the total porosity and the volume of harmful pores in hardened paste containing 25\% GSP were significantly reduced. Sample MS25 had lower total porosity than sample MC. However, the volumes of harmful pores of both pastes showed little difference. 


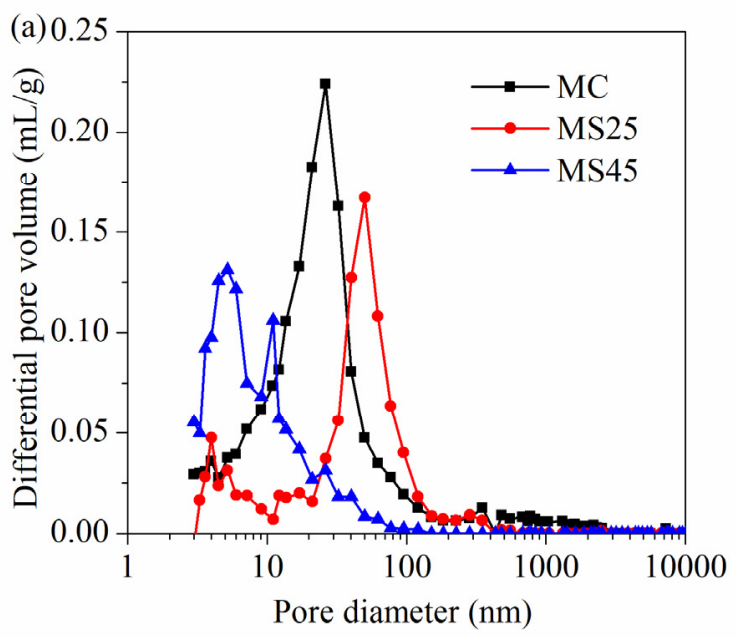

(a)

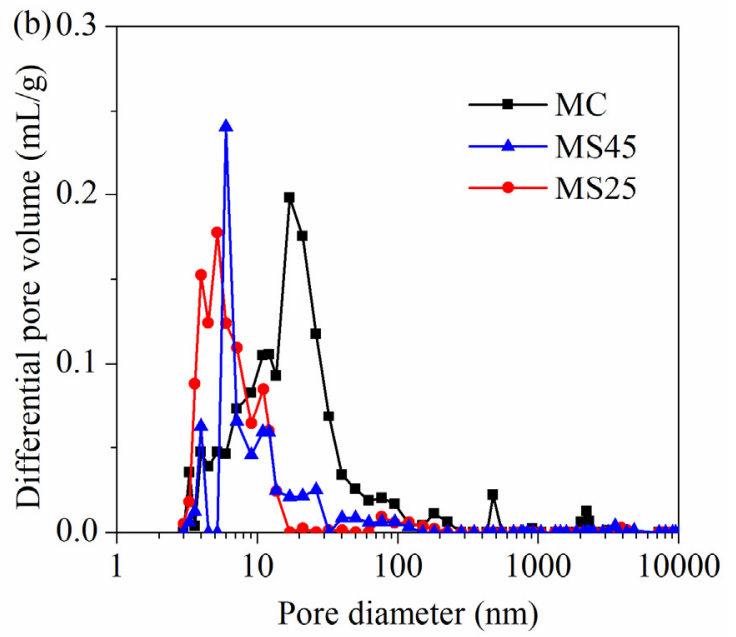

(b)

Figure 8. Differential pore volume of hardened pastes under temperature-matching curing conditions: (a) at $28 \mathrm{~d}$; (b) at $90 \mathrm{~d}$.

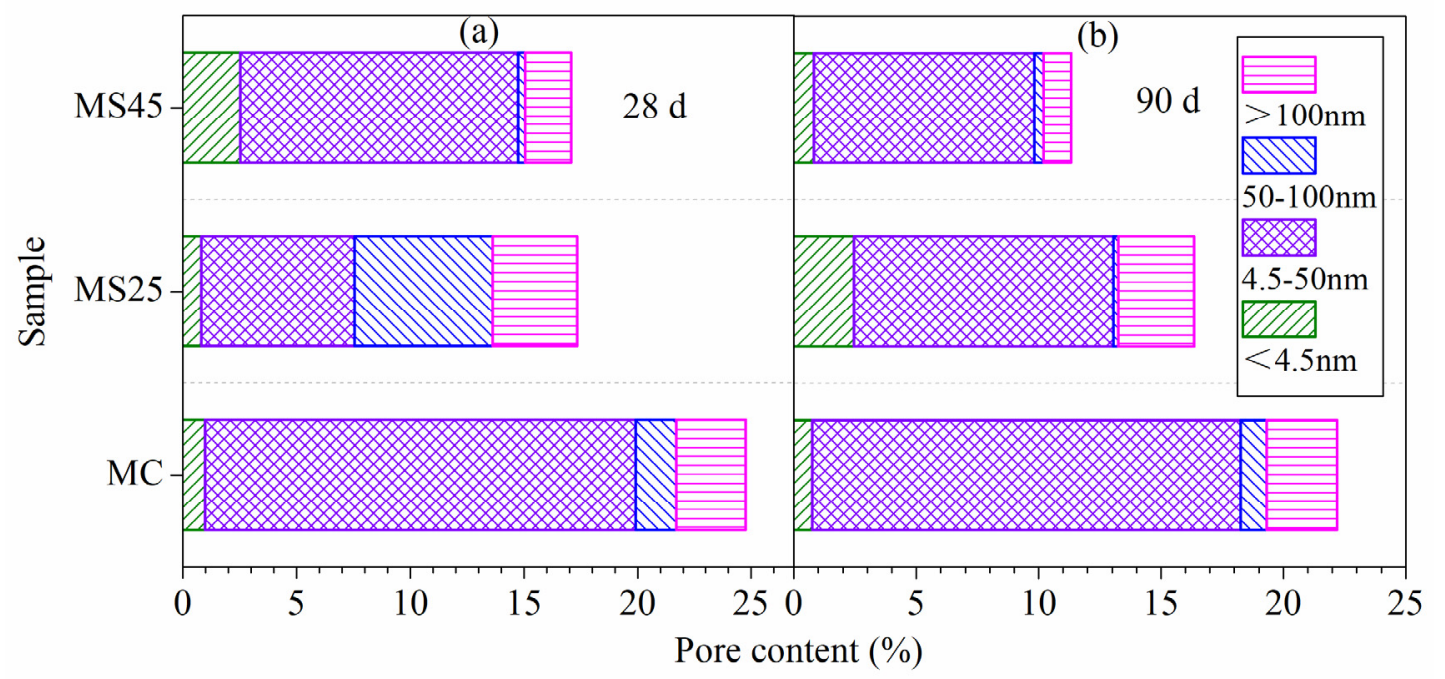

Figure 9. The pore size distribution of hardened pastes under temperature-matching curing conditions: (a) at $28 \mathrm{~d}$; (b) at $90 \mathrm{~d}$.

\section{5. $\mathrm{CH}$ Content}

The main hydration products of cement after $110^{\circ} \mathrm{C}$ are $\mathrm{CH}$ and $\mathrm{C}-\mathrm{S}-\mathrm{H}$ gel. TG and DTG analyses can express the mass loss resulting from the decomposition of the hydration products. TG and DTG curves of hardened pastes under standard curing conditions at different ages are presented in Figure 10. It is obvious that the mass loss of sample SC was lower than that of samples SS25 and SS45 at the same ages, especially at early ages ( $14 \mathrm{~d}$ and 28 d). However, the gap between samples SS25 and SS45 was small. As seen from the DTG curves, there are two distinct peaks. One peak represents the dehydration of the C-S-H gel before $200{ }^{\circ} \mathrm{C}$, and the other is associated with the decomposition of $\mathrm{CH}$ within a temperature range of $400{ }^{\circ} \mathrm{C}-500{ }^{\circ} \mathrm{C}[46,47]$. It is worth noting that a smaller peak can be found at approximately $800{ }^{\circ} \mathrm{C}$, especially at $90 \mathrm{~d}$. This peak is related to the decomposition of $\mathrm{CaCO}_{3}$ originating from the carbonation of $\mathrm{CH}$. The total $\mathrm{CH}$ content was calculated based on the mass losses, corresponding to the decomposition of $\mathrm{CH}$ and $\mathrm{CaCO}_{3}$. 


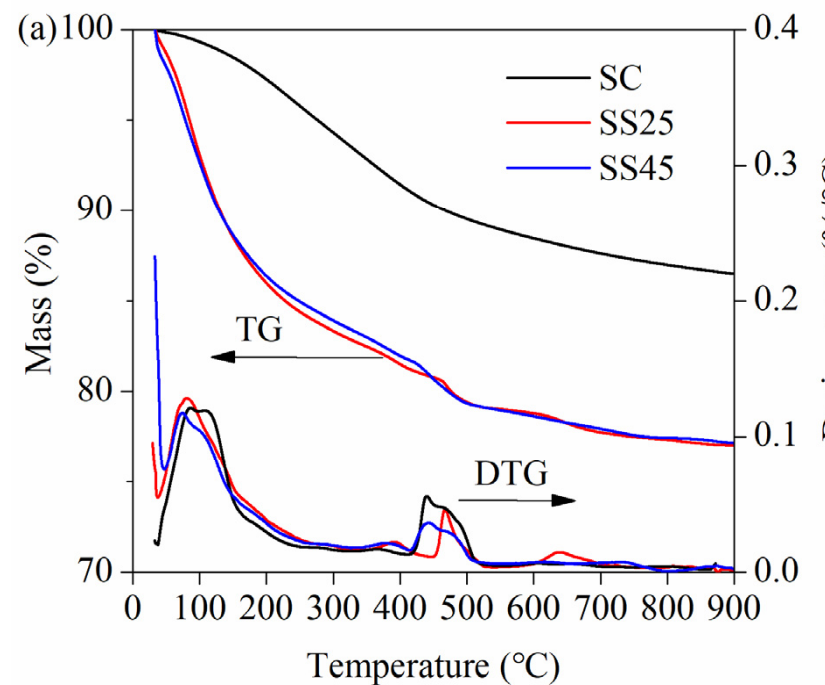

(a)

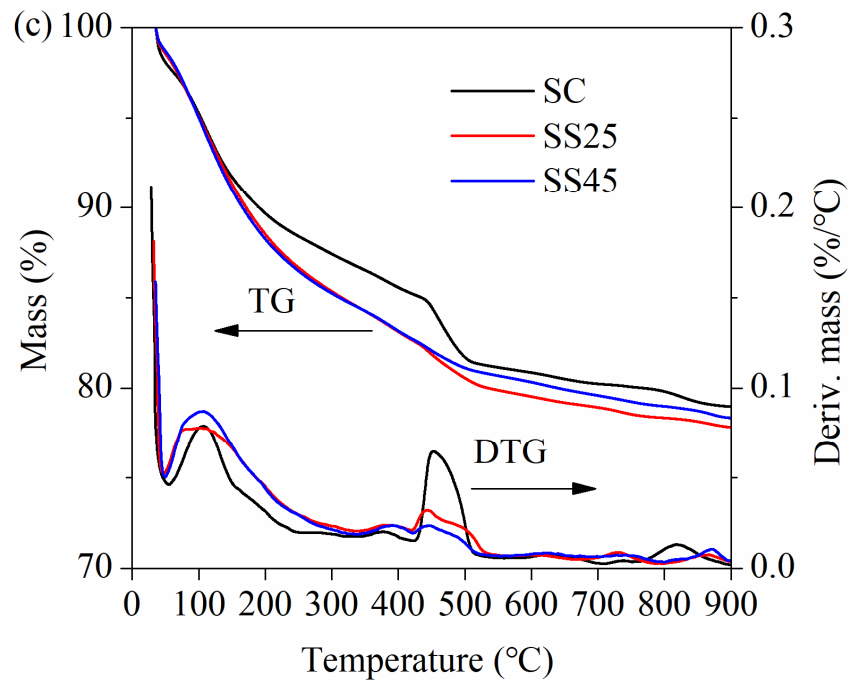

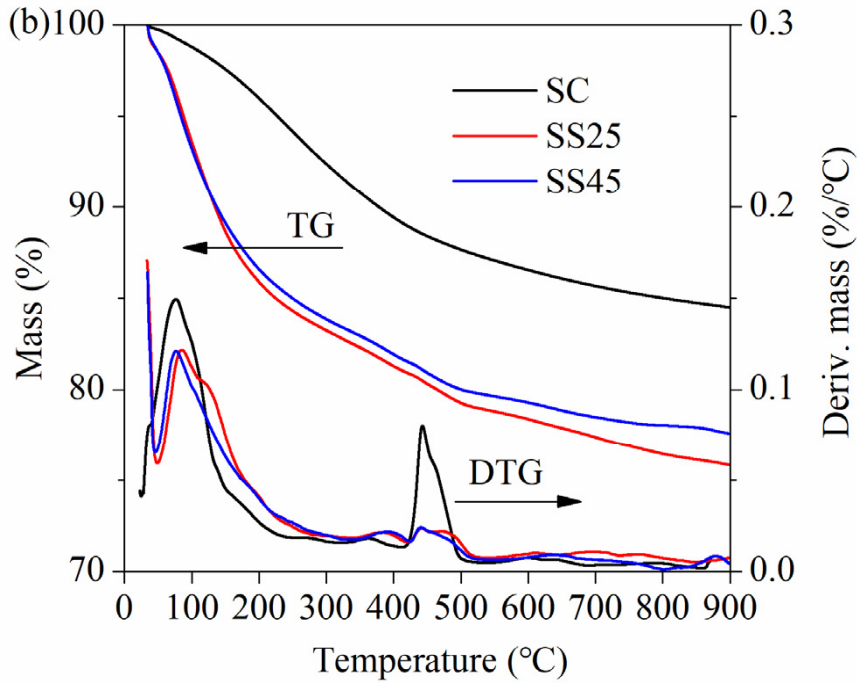

(b)

(c)

Figure 10. Thermogravimetric (TG) and derivative thermogravimetric (DTG) curves of hardened pastes under standard curing conditions: (a) at $14 \mathrm{~d}$; (b) at $28 \mathrm{~d}$; (c) at $90 \mathrm{~d}$.

Therefore, the $\mathrm{CH}$ content of hardened paste at different ages under standard curing conditions is shown in Figure 11. It is clear that the $\mathrm{CH}$ content declined as the incorporation of GSP increased at early and late ages, which can be primarily attributed to the reduction in the cement content. Furthermore, unlike cement, GSP does not produce $\mathrm{CH}$, but consumes a certain amount of $\mathrm{CH}$ due to its pozzolanic reaction. In order to better explain the influence of GSP on the cement system, the $\mathrm{CH}$ contents of plain cement systems were calculated using reduction factors of 0.75 (25\% GSP) and 0.55 (45\% GSP), respectively. The calculation results are also marked in Figure 11. At $14 \mathrm{~d}$, compared to those of the cement after the calculation with reduction factors of 0.75 and 0.55 , the $\mathrm{CH}$ contents of samples SS25 and SS45 were significantly higher. This indicates that the promoting effects of GSP on the cementitious system exceeded the pozzolanic effect of GSP. These promoting effects on cement hydration can be attributed to the dilution effect and the nucleation effect, which forms a higher effective water/cement ratio and a larger growth space for hydration 
products. At an early age, hydration of cement in the cementitious system is dominant. At $28 \mathrm{~d}$, the $\mathrm{CH}$ contents in the cement paste after calculation and the corresponding hardened paste containing GSP showed little difference. However, with further hydration, the pozzolanic reaction of GSP consumed more $\mathrm{CH}$, leading to a lower $\mathrm{CH}$ content in composite systems at $90 \mathrm{~d}$.

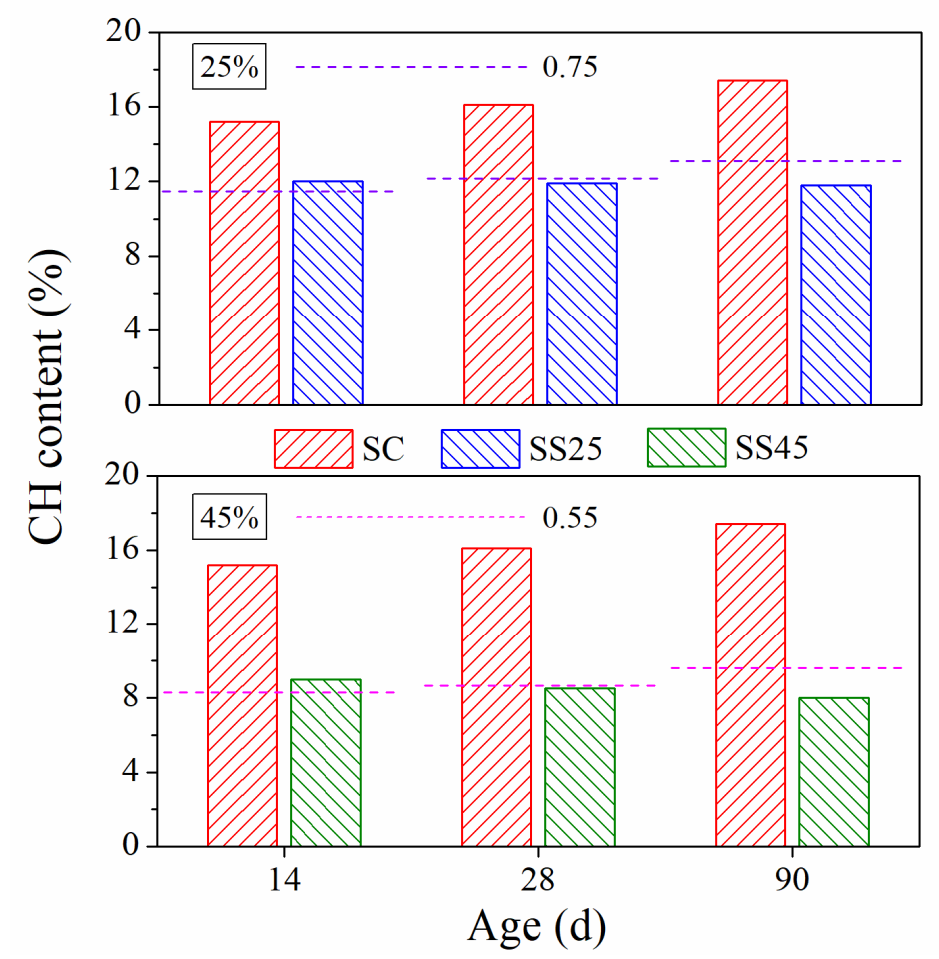

Figure 11. $\mathrm{CH}$ content of hardened pastes under standard curing conditions.

The TG and DTG curves of hardened pastes at different ages under temperaturematching curing conditions are presented in Figure 12. As shown in Figure 12, the trend in mass losses was obviously different from that observed under standard curing conditions (Figure 10). The gaps between samples MC, MS25 and MS45 were relatively small at all ages. There are also two endothermic peaks on the DTG curves at approximately $100{ }^{\circ} \mathrm{C}$ and $450{ }^{\circ} \mathrm{C}$, corresponding to the sequential decomposition of $\mathrm{C}-\mathrm{S}-\mathrm{H}$ gel and $\mathrm{CH}$ crystals. Another absorption peak is located at approximately $650{ }^{\circ} \mathrm{C}$, which represents the decomposition of $\mathrm{CaCO}_{3}$.

The $\mathrm{CH}$ contents of different hardened pastes, including measured values and normalization marks, under temperature-matching curing conditions are indicated in Figure 13. At $14 \mathrm{~d}$, the $\mathrm{CH}$ contents in the cement paste after calculation and the corresponding hardened paste containing GSP showed little difference. This indicates that the $\mathrm{CH}$ content remained balanced between production from cement hydration and consumption due to the pozzolanic reaction of GSP. Currently, the promoting effect of GSP on the cementitious system can compensate for its negative effect on $\mathrm{CH}$ content due to the pozzolanic effect. At $28 \mathrm{~d}$, compared to those of the cement after calculation with reduction factors of 0.75 and 0.55 , the CH contents of samples SS25 and SS45 were significantly lower. At $90 \mathrm{~d}$, the gap in $\mathrm{CH}$ contents between the cement paste and hardened paste containing GSP became wider. This indicates that the pozzolanic effect of GSP proves its importance with further hydration. Compared to that observed under standard curing conditions, the gap in the $\mathrm{CH}$ content at $14 \mathrm{~d}$ was obviously smaller under temperature-matching curing condition. Elevated curing temperature has a greater impact on the pozzolanic reaction of GSP, consuming more $\mathrm{CH}$. 


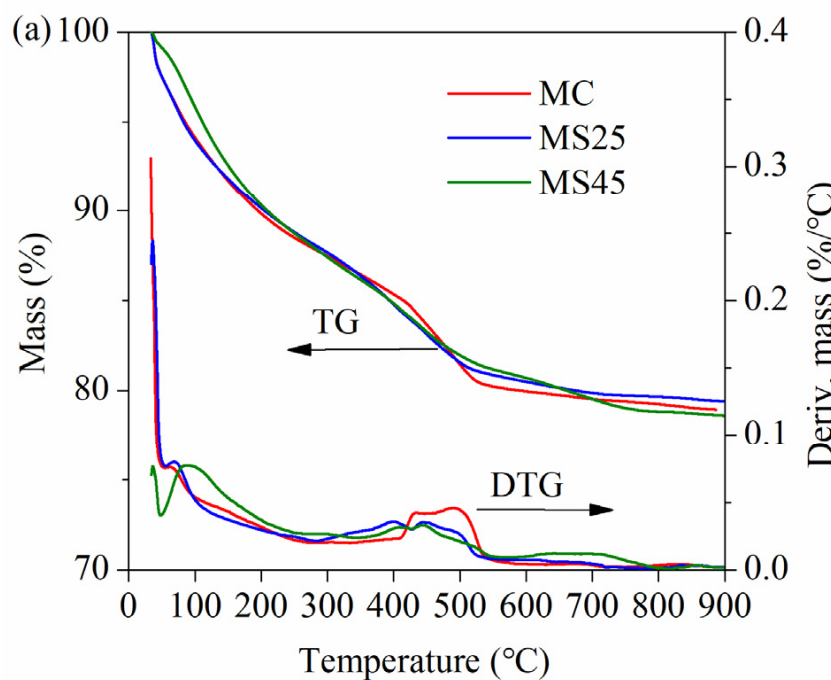

(a)

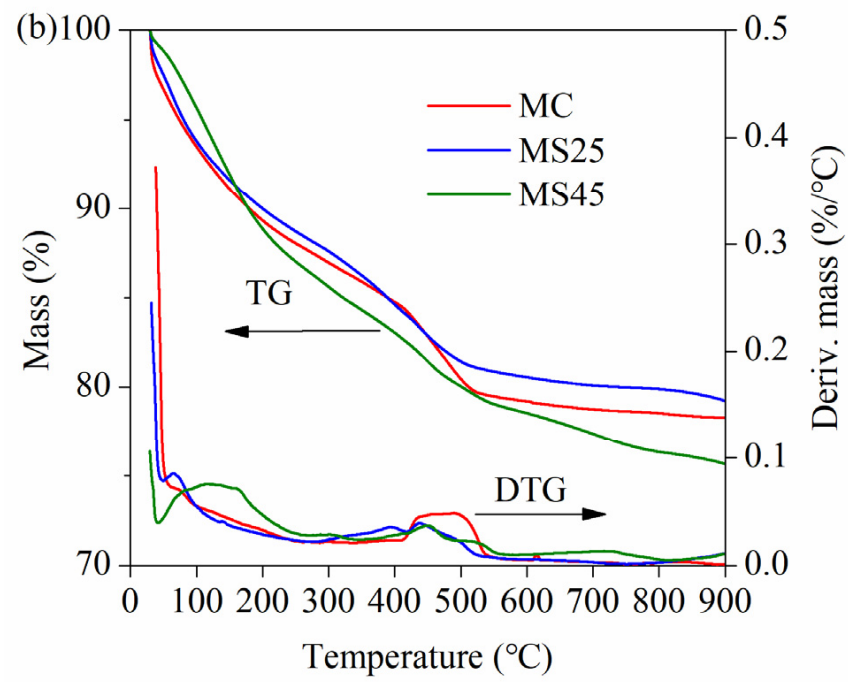

(b)

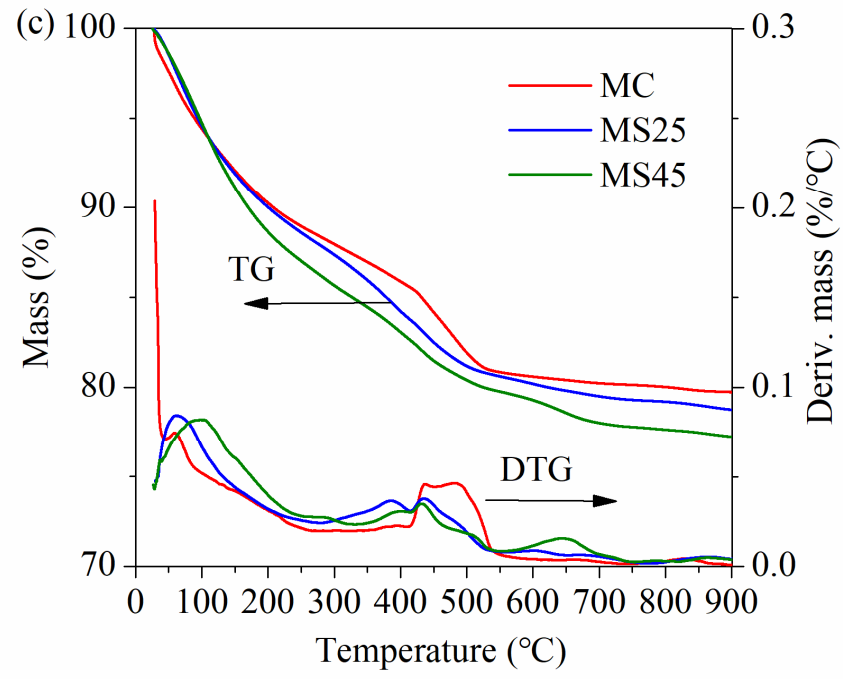

(c)

Figure 12. TG and DTG curves of hardened pastes under temperature-matching curing conditions: (a) at $14 \mathrm{~d}$; (b) at $28 \mathrm{~d}$; (c) at $90 \mathrm{~d}$.

\subsection{Non-Evaporable Water Content}

The non-evaporable water contents of hardened paste under two curing conditions are presented in Figure 14a,b, respectively. The lowest non-evaporable water content of hardened paste exceeded $12 \%$ under both curing conditions. Under standard curing condition, the non-evaporable water content of hardened paste containing GSP was slightly higher than that of sample SC. In particular, hardened paste containing 25\% GSP showed the highest non-evaporable water content. This indicates that the promoting effects, including the dilution effect and the nucleation effect of GSP on the cement hydration, were obvious at early and late ages. The results agree with the results of the adiabatic temperature rise of concrete (Figure 1). In theory, the hydration of Portland cement per gram produces $0.25 \mathrm{~g}$ of non-evaporable water, but the pozzolanic reaction of slag per gram generates $0.30 \mathrm{~g}$ of non-evaporable water [48]. Meanwhile, increasing the fineness of active powder has a more positive effect on the pozzolanic reaction [48]. Therefore, the faster reaction of GSP results with a higher temperature rise rate was observed for sample SS25 (Figure 1), along with the 
higher non-evaporable water content of sample SS25. However, the gap in non-evaporable water contents between samples SC and SS45 was relatively small, resulting from a sharp reduction in cement content. Combined with the results of compressive strength under two curing conditions, sample SS45 had the highest compressive strength. The compressive strength of concrete depends not only on the amount of hydration products, it is also closely related to the pore structure. Sample SS45 had the lowest total porosity and volume of harmful pores, which resulted in the highest compressive strength.

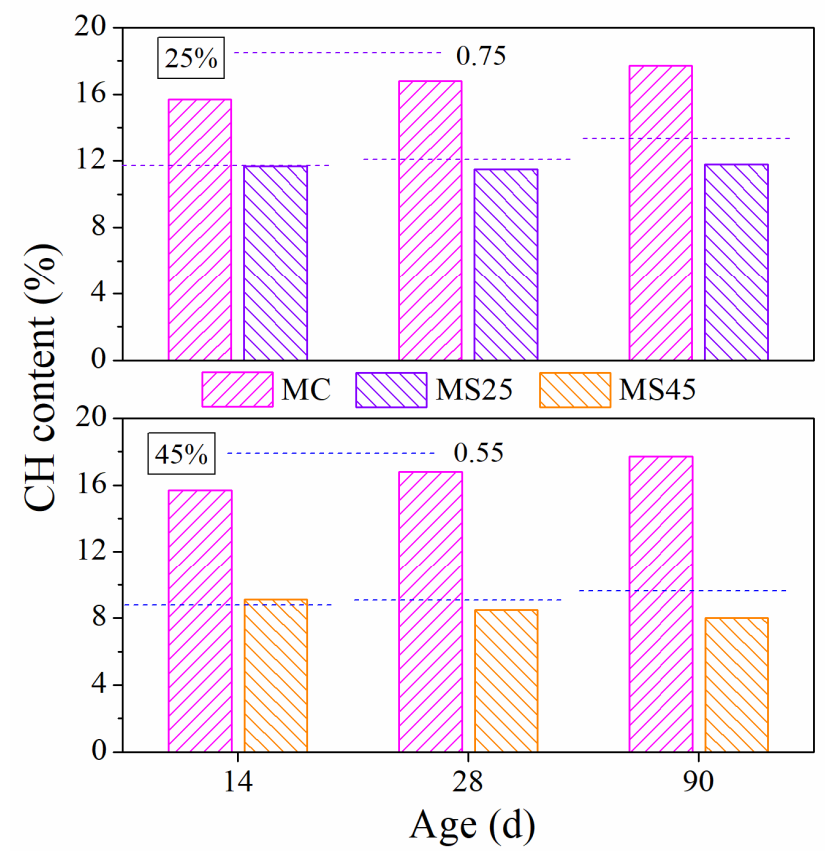

Figure 13. $\mathrm{CH}$ content of hardened pastes under temperature-matching curing conditions.

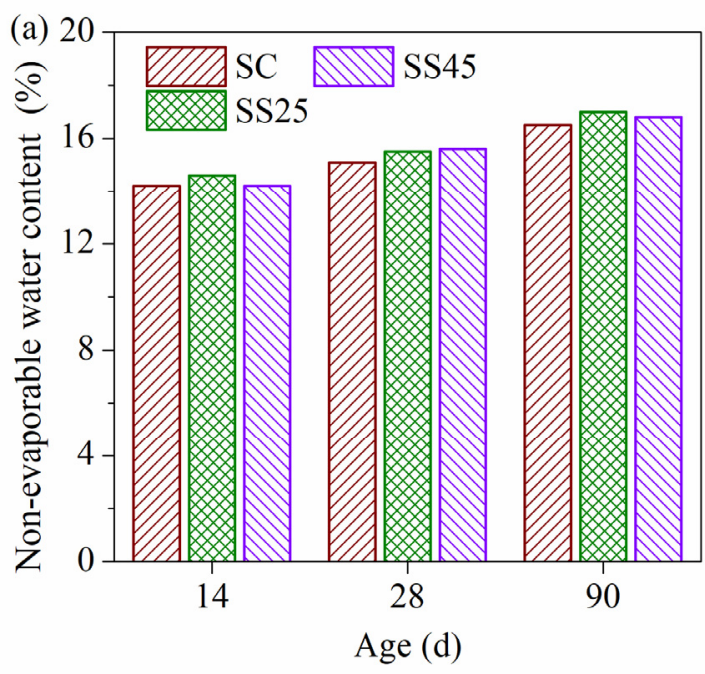

(a)

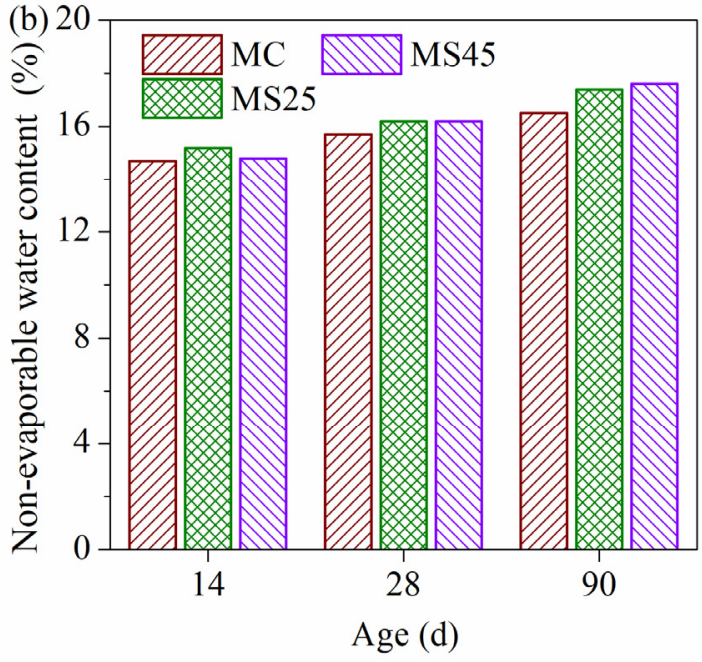

(b)

Figure 14. Non-evaporable water content of hardened pastes: (a) under standard curing conditions; (b) under temperaturematching curing conditions.

Under temperature-matching curing conditions, the trend of the non-evaporable water content was similar to that under standard curing conditions (Figure 14a). However, the non-evaporable water content of hardened paste became higher than that under standard curing conditions. Increasing the early curing temperature evidently improves the hydra- 
tion rate of the plain cement and composite binder. Meanwhile, the highest non-evaporable water content was observed for sample SS45 at $90 \mathrm{~d}$. Replacing cement with GSP markedly increased the late non-evaporable water content under temperature-matching curing conditions. It is worth noting that the non-evaporable water content of hardened paste containing GSP under two curing conditions reached or exceeded the content of cement paste after 14 $\mathrm{d}$ of curing. A previous study on ordinary slag showed that the same non-evaporable water content with replacement rates of $50 \%-70 \%$ can be achieved after $60 \mathrm{~d}$ of curing $[28,49]$. This indicates that the fineness of slag plays an important role in cement hydration and the pozzolanic reaction of mineral admixtures.

\section{Conclusions}

(1) Adding 25\% GSP increases the adiabatic temperature rise of high-strength concrete due to the promoting effects on cement hydration, whereas adding $45 \%$ GSP decreases the adiabatic temperature rise, which can be attributed to a reduction in cement content.

(2) Compared to the compressive strength of plain cement concrete, the growth rates of strength at different ages due to the addition of GSP under temperature-matching curing conditions are higher than those under standard curing temperature. Temperaturematching curing conditions have a positive effect on the development of the late compressive strength of GSP concrete.

(3) Compared to plain cement systems, cementitious material systems containing GSP tend to have lower total porosity and a lower volume of harmful pores. The dense pore structure of the GSP system leads to better chloride ion penetrability resistance of the concrete, which is more distinct under early temperature-matching curing conditions. Increasing the curing temperature has a greater influence on high-strength concrete mixed with $25 \%$ GSP.

(4) The improvement effects of incorporating GSP on the late non-evaporable water content of hardened paste are significant under early temperature matching curing conditions. However, the effect of elevated temperatures on the early non-evaporable water content are limited. Increasing early curing temperatures has a more obvious effect on the pozzolanic reaction of GSP than the hydration of cement.

Author Contributions: Conceptualization, Y.Z.; methodology, Y.Z. and Z.Z.; software, Y.Z. and Z.Z.; validation, J.S. and Z.Z.; writing — original draft preparation, J.S.; writing-review and editing, J.S.; All authors have read and agreed to the published version of the manuscript.

Funding: This research was funded by the National Natural Science Foundation of China, grant number 52008229 .

Institutional Review Board Statement: Not applicable.

Informed Consent Statement: Not applicable.

Data Availability Statement: Data is contained within the article.

Conflicts of Interest: The authors declare no conflict of interest.

\section{References}

1. Mengxiao, S.; Qiang, W.; Zhikai, Z. Comparison of the properties between high-volume fly ash concrete and high-volume steel slag concrete under temperature matching curing condition. Constr. Build. Mater. 2015, 98, 649-655. [CrossRef]

2. Alaskar, A.; Albidah, A.; Alqarni, A.S.; Alyousef, R.; Mohammadhosseini, H. Performance evaluation of high-strength concrete reinforced with basalt fibers exposed to elevated temperatures. J. Build. Eng. 2021, 35, 102108. [CrossRef]

3. Shen, D.; Liu, C.; Jiang, J.; Kang, J.; Li, M. Influence of super absorbent polymers on early-age behavior and tensile creep of internal curing high strength concrete. Constr. Build. Mater. 2020, 258, 120068. [CrossRef]

4. Shen, D.; Kang, J.; Jiao, Y.; Li, M.; Li, C. Effects of different silica fume dosages on early-age behavior and cracking resistance of high strength concrete under restrained condition. Constr. Build. Mater. 2020, 263, 120218. [CrossRef]

5. Evram, A.; Akçaoğlu, T.; Ramyar, K.; Çubukçuoğlu, B. Effects of waste electronic plastic and marble dust on hardened properties of high strength concrete. Constr. Build. Mater. 2020, 263, 120928. [CrossRef] 
6. Al-Yousuf, A.; Pokharel, T.; Lee, J.; Gad, E.; Abdouka, K.; Sanjayan, J. Effect of fly ash and slag on properties of normal and high strength concrete including fracture energy by wedge splitting test: Experimental and numerical investigations. Constr. Build. Mater. 2021, 271, 121553. [CrossRef]

7. Kushnir, A.R.; Heap, M.J.; Griffiths, L.; Wadsworth, F.B.; Langella, A.; Baud, P.; Reuschlé, T.; Kendrick, J.E.; Utley, J.E. The fire resistance of high-strength concrete containing natural zeolites. Cem. Concr. Compos. 2021, 116, 103897. [CrossRef]

8. Liu, S.; Zhang, T.; Guo, Y.; Wei, J.; Yu, Q. Effects of SCMs particles on the compressive strength of micro-structurally designed cement paste: Inherent characteristic effect, particle size refinement effect, and hydration effect. Powder Technol. 2018, 330, 1-11. [CrossRef]

9. Aprianti, E. A huge number of artificial waste material can be supplementary cementitious material (SCM) for concrete production-A review part II. J. Clean. Prod. 2017, 142, 4178-4194. [CrossRef]

10. Samad, S.; Shah, A. Role of binary cement including Supplementary Cementitious Material (SCM), in production of environmentally sustainable concrete: A critical review. Int. J. Sustain. Built Environ. 2017, 6, 663-674. [CrossRef]

11. Zhuang, S.; Wang, Q. Inhibition mechanisms of steel slag on the early-age hydration of cement. Cem. Concr. Res. 2021, 140, 106283. [CrossRef]

12. Papayianni, I.; Anastasiou, E. Production of high-strength concrete using high volume of industrial by-products. Constr. Build. Mater. 2010, 24, 1412-1417. [CrossRef]

13. Wang, D.; Wang, Q.; Huang, Z. Reuse of copper slag as a supplementary cementitious material: Reactivity and safety. Resour. Conserv. Recycl. 2020, 162, 105037. [CrossRef]

14. Khalil, E.A.B.; Anwar, M. Carbonation of ternary cementitious concrete systems containing fly ash and silica fume. Water Sci. 2015, 29, 36-44. [CrossRef]

15. Palod, R.; Deo, S.; Ramtekkar, G. Effect on mechanical performance, early age shrinkage and electrical resistivity of ternary blended concrete containing blast furnace slag and steel slag. Mater. Today Proc. 2020, 32, 917-922. [CrossRef]

16. Cordeiro, G.; Filho, R.T.; Tavares, L.; Fairbairn, E. Experimental characterization of binary and ternary blended-cement concretes containing ultrafine residual rice husk and sugar cane bagasse ashes. Constr. Build. Mater. 2012, 29, 641-646. [CrossRef]

17. Lemonis, N.; Tsakiridis, P.; Katsiotis, N.; Antiohos, S.; Papageorgiou, D.; Beazi-Katsioti, M. Hydration study of ternary blended cements containing ferronickel slag and natural pozzolan. Constr. Build. Mater. 2015, 81, 130-139. [CrossRef]

18. Chindaprasirt, P.; Kroehong, W.; Damrongwiriyanupap, N.; Suriyo, W.; Jaturapitakkul, C. Mechanical properties, chloride resistance and microstructure of Portland fly ash cement concrete containing high volume bagasse ash. J. Build. Eng. 2020, 31, 101415. [CrossRef]

19. Jeong, Y.; Park, H.; Jun, Y.; Jeong, J.-H.; Oh, J.E. Microstructural verification of the strength performance of ternary blended cement systems with high volumes of fly ash and GGBFS. Constr. Build. Mater. 2015, 95, 96-107. [CrossRef]

20. Cheah, C.B.; Tiong, L.L.; Ng, E.P.; Oo, C.W. The engineering performance of concrete containing high volume of ground granulated blast furnace slag and pulverized fly ash with polycarboxylate-based superplasticizer. Constr. Build. Mater. 2019, 202, 909-921. [CrossRef]

21. Sun, W.; Yan, H.; Zhan, B. Analysis of mechanism on water-reducing effect of fine ground slag, high-calcium fly ash, and low-calcium fly ash. Cem. Concr. Res. 2003, 33, 1119-1125. [CrossRef]

22. Wang, Y.; Liu, X.; Zhang, W.; Li, Z.; Zhang, Y.; Li, Y.; Ren, Y. Effects of Si / Al ratio on the efflorescence and properties of fly ash based geopolymer. J. Clean. Prod. 2020, 244, 118852. [CrossRef]

23. Wang, D.; Wang, Q.; Huang, Z. New insights into the early reaction of $\mathrm{NaOH}$-activated slag in the presence of $\mathrm{CaSO}_{4}$. Compos. Part B Eng. 2020, 198, 108207. [CrossRef]

24. Juenger, M.C.; Snellings, R.; Bernal, S.A. Supplementary cementitious materials: New sources, characterization, and performance insights. Cem. Concr. Res. 2019, 122, 257-273. [CrossRef]

25. Piatak, N.M.; Parsons, M.B.; Seal, R.R. Characteristics and environmental aspects of slag: A review. Appl. Geochem. 2015, 57, 236-266. [CrossRef]

26. Tiwari, M.K.; Bajpai, S.; Dewangan, U.; Tamrakar, R.K. Suitability of leaching test methods for fly ash and slag: A review. J. Radiat. Res. Appl. Sci. 2015, 8, 523-537. [CrossRef]

27. Jindal, B.B.; Jangra, P.; Garg, A. Effects of ultra fine slag as mineral admixture on the compressive strength, water absorption and permeability of rice husk ash based geopolymer concrete. Mater. Today Proc. 2020, 32, 871-877. [CrossRef]

28. Hussain, F.; Kaur, I.; Hussain, A. Reviewing the influence of GGBFS on concrete properties. Mater. Today Proc. 2020, 32, 997-1004. [CrossRef]

29. Samchenko, S.; Kozlova, I.; Zorin, D. The effect of ultrafine fillers on the properties of cement-sand mortars. Mater. Today Proc. 2019, 19, 2096-2099. [CrossRef]

30. Siddique, R.; Bennacer, R. Use of iron and steel industry by-product (GGBS) in cement paste and mortar. Resour. Conserv. Recycl. 2012, 69, 29-34. [CrossRef]

31. Özbay, E.; Erdemir, M.; Durmuş, H.I. Utilization and efficiency of ground granulated blast furnace slag on concrete properties-A review. Constr. Build. Mater. 2016, 105, 423-434. [CrossRef]

32. Gao, D.; Meng, Y.; Yang, L.; Tang, J.; Lv, M. Effect of ground granulated blast furnace slag on the properties of calcium sulfoaluminate cement. Constr. Build. Mater. 2019, 227, 116665. [CrossRef] 
33. Rashad, A.M. An overview on rheology, mechanical properties and durability of high-volume slag used as a cement replacement in paste, mortar and concrete. Constr. Build. Mater. 2018, 187, 89-117. [CrossRef]

34. Amran, M.; Murali, G.; Khalid, N.H.A.; Fediuk, R.; Ozbakkaloglu, T.; Lee, Y.H.; Haruna, S.; Lee, Y.Y. Slag uses in making an ecofriendly and sustainable concrete: A review. Constr. Build. Mater. 2021, 272, 121942. [CrossRef]

35. He, X.; Ma, M.; Su, Y.; Lan, M.; Zheng, Z.; Wang, T.; Strnadel, B.; Zeng, S. The effect of ultrahigh volume ultrafine blast furnace slag on the properties of cement pastes. Constr. Build. Mater. 2018, 189, 438-447. [CrossRef]

36. Liu, Y.; Zhang, Z.; Hou, G.; Yan, P. Preparation of sustainable and green cement-based composite binders with high-volume steel slag powder and ultrafine blast furnace slag powder. J. Clean. Prod. 2021, 289, 125133. [CrossRef]

37. Zhang, T.; Tian, W.; Guo, Y.; Bogush, A.; Khayrulina, E.; Wei, J.; Yu, Q. The volumetric stability, chloride binding capacity and stability of the Portland cement-GBFS pastes: An approach from the viewpoint of hydration products. Constr. Build. Mater. 2019, 205, 357-367. [CrossRef]

38. Mohan, A.; Mini, K. Strength and durability studies of SCC incorporating silica fume and ultra fine GGBS. Constr. Build. Mater. 2018, 171, 919-928. [CrossRef]

39. Kumar, M.P.; Mini, K.; Rangarajan, M. Ultrafine GGBS and calcium nitrate as concrete admixtures for improved mechanical properties and corrosion resistance. Constr. Build. Mater. 2018, 182, 249-257. [CrossRef]

40. Zhao, H.; Jiang, K.; Yang, R.; Tang, Y.; Liu, J. Experimental and theoretical analysis on coupled effect of hydration, temperature and humidity in early-age cement-based materials. Int. J. Heat Mass Transf. 2020, 146, 118784. [CrossRef]

41. Hou, D.; Zhang, W.; Sun, M.; Wang, P.; Wang, M.; Zhang, J.; Li, Z. Modified Lucas-Washburn function of capillary transport in the calcium silicate hydrate gel pore: A coarse-grained molecular dynamics study. Cem. Concr. Res. 2020, 136, 106166. [CrossRef]

42. Tennis, P.D.; Jennings, H.M. A model for two types of calcium silicate hydrate in the microstructure of Portland cement pastes. Cem. Concr. Res. 2000, 30, 855-863. [CrossRef]

43. Brouwers, H. The work of Powers and Brownyard revisited: Part 1. Cem. Concr. Res. 2004, 34, 1697-1716. [CrossRef]

44. Jennings, H.M.; Dalgleish, B.J.; Pratt, P.L. Morphological Development of Hydrating Tricalcium Silicate as Examined by Electron Microscopy Techniques. J. Am. Ceram. Soc. 1981, 64, 567-572. [CrossRef]

45. Mehta, P.K.; Manmohan, D. Pore size distribution and permeability of hardened cement paste. In Proceedings of the 7th International Congress on the Chemistry of Cement, Paris, France, 1-4 July 1980; pp. 1-5.

46. Feng, J.; Liu, S.; Wang, Z. Effects of ultrafine fly ash on the properties of high-strength concrete. J. Therm. Anal. Calorim. 2015, 121, 1213-1223. [CrossRef]

47. Yan, C.; Zhao, H.; Zhang, J.; Liu, S.; Yang, Z. The cementitious composites using calcium silicate slag as partial cement. J. Clean. Prod. 2020, 256, 120514. [CrossRef]

48. Han, F.; Luo, A.; Liu, J.; Zhang, Z. Properties of high-volume iron tailing powder concrete under different curing conditions. Constr. Build. Mater. 2020, 241, 118108. [CrossRef]

49. Attari, A.; McNally, C.; Richardson, M.G. A combined SEM-Calorimetric approach for assessing hydration and porosity development in GGBS concrete. Cem. Concr. Compos. 2016, 68, 46-56. [CrossRef] 